\title{
UN TEMA COSTUMBRISTA: LAS HORAS DE LA CIUDAD
}

José ESCOBAR

Glendon College, York University (Toronto)

\section{La literatura de la ciudad}

La literatura de la ciudad se inicia en el siglo XVIII. Hasta entonces la imagen de la ciudad había aparecido en las obras literarias desde diversas perspectivas en épocas diferentes. En la literatua española vemos cómo Burgos se vislumbra en los primeros versos conocidos del Cantar de Mio Cid, el héroe castellano cruzando la ciudad en el silencio de la noche camino del destierro. Luego Valencia, el esposo y padre orgulloso de su conquista la muestra satifecho a su esposa y a sus hijas: la ciudad, la huerta, el mar. El bullicio urbano aparece en el Libro de buen amor, la plaza del pueblo donde Don Melón fue a hablar con doña Endrina. La ciudad es el espacio en que se mueve Celestina y Lázaro de Tormes callejea acompañando al escudero por Toledo. La ciudad es el escenario de la novela picaresca y El diablo cojuelo, que luego va a ser símbolo del costumbrismo urbano, levanta los tejados descubriendo lo que pasa en los interiores de las casas de Madrid mientras que en sus calles ocurren tantos lances de las comedias de capa y espada. Juan de Zabaleta presenta a los habitantes de la ciudad como objeto del la sátira moral en El día de fiesta por la mañana y El día de fiesta por la tarde. Con intención religiosa, Zabaleta predica contra las malas costumbres de estos ciudadanos, consideradas como hábitos de la naturaleza humana sin determinación histórica de sus circunstancias sociales y urbanas La ciudad es el escenario donde se sitúa la sátira moral de la conducta humana o trancurre la acción de la novela o la comedia, pero no tiene protagonismo en sí misma. Esto no ocurre hasta el siglo XVIII, cuando en el proceso revolucionario que es la Ilustración se realiza la transformación del concepto de mímesis literaria cuyo objeto ya no es la natu- 
raleza en general, sino lo particular y local de las ciucunstancias sociales (Escobar 1988, Álvarez Barrientos 1990, Ferraz Martínez 2003). Con ello se inicia una nueva poética. Ya no se trata de presentar la ficción literaria como un reflejo de la eterna naturaleza humana, sino de captar el aspecto cambiante de la sociedad en el momento histórico. Es una mímesis de lo circunstancial, de las circunstancias determinadas por la actualidad, que es lo que se va a entender con el término «costumbre» en la crítica literaria moderna. El objeto de la mímesis ya no es la naturaleza, sino la sociedad, es decir, la «vida civil» o «sociedad civil»), la vida de la clase media en la ciudad. La Ilustración dieciochesca en cuyo marco surge este nuevo modo de escribir es un movimiento revolucionario que nos lleva del mundo rural al mundo urbano en que se despliega la literatura de la vida en sociedad. Es lo que hemos llamado «mímesis costumbrista» (Escobar 1988), mímesis moderna que promueve una poética de la ciudad. En sus orígenes dieciochescos, el modo de escribir que a finales del XIX empieza a llamarse «costumbrismo» (Salomon 1968, pág. 342) es literatura urbana, literatura que tiene por objeto la vida de la ciudad, aunque el sabor local decimonónico derive al folklorismo regionalista, a la valoración del campo frente a la ciudad como reacción ideológica a la civilización urbana de la modernidad.

La prensa periódica en la tradición que inauguran Addison y Steele con su Spectator (1711-1714) es el vehículo apropiado de esta nueva literatura. Los periódicos pronto llegan a ser la literatura de la ciudad que en sus escritos reflejan las vivencias urbanas. En ellos el vecindario es el protagonista. Hablan a los lectores urbanos sobre ellos mismos, sobre la normalidad de su vivir cotidiano en sus calles y paseos, en sus casas, en sus reuniones, tertulias y asambleas, en las tiendas, teatros y cafés. Esta nueva corriente literaria europea inspira en España, entre otros, la escritura de José Clavijo y Fajardo en su serie periódica de El Pensador entre 1762 y 1767 (Escobar 1973, págs. 92-118; Marún 1983). El escritor del periódico quiere ser la voz de la ciudad como expresión de las observaciones que realiza en su continuo callejeo por Madrid, que es su mundo, de tal modo que luego, en una reimpresión, se va llamar El Pensador Matritense. ' En sus paseatas, la Puerta del Sol es el punto de referencia urbano en la ensambladura de los diversos espacios de la ciudad por la que transita y que, como gran fuente de conocimiento, sustituye a la universidad: «Las horas del día que tengo libres las empleo en examinar toda clase de gentes. Tan pronto me introduzco en una asamblea de políticos, como en un estrado de damas... Visito los teatros, los paseos y las tiendas; entablo mis diálogos con el sastre, el zapatero y el aguador; la Puerta del Sol me consume algunos ratos; y en estas escuelas aprendo más en un día, que pudiera en una universidad en diez años»». (I, 12-14) En su transitar por los lugares donde

\footnotetext{
' Con este título se reimprime en Barcelona, Pedro Ángel de Tarazona, s. a. [1773-1774].
} 
concurren tos vecinos, el observador se confunde con ellos en una relación familiar que abarca del político al aguador. Quiere ofrecer, en la mirada del traseúnte, la realidad inmediata de la ciudad. Como los costumbristas del siglo siguiente, Clavijo y Fajardo expresa en El Pensador el deseo de acercar la mirada a lo que nos rodea, proponiendo que, en vez de informarnos de asuntos lejanos, «volvamos los ojos y nos informemos de lo que pasa entre nosotros y en nuestros mismos interiores» (I, 10-11). Es la literatura de lo que pasa. (Escobar 1994).

Karlheinz Stierle $(1986,1993)$ ha estudiado el significado de lo que él considera «el descubrimiento de la ciudad» en la literatura europea, descubrimiento que, en vísperas de la Revolución Francesa, se realiza a partir del París de la Ilustración, primera gran ciudad de Europa que alcanza una conciencia de sí misma: «En París se despliega desde la Ilustración tardía una literatura de la ciudad ( «Stadliteratur»), que por vez primera trata de penetrar la ciudad misma y en toda la diversidad de sus aspectos y relaciones, encontrando así formas de representación orientadoras de la literatura de la gran ciudad que se desarrolla en el siglo XIX» (Stierle 1986, pág. 81), Esta representación literaria de la ciudad la construye Louis-Sébartien Mercier en los doce tomos que publica entre 1781 y 1788 con el título de Tableau de Paris. «La galería de tipos y profesiones de los que viven en la ciudad parece inagotable -dice Stierle-... Nunca antes ha sido una ciudad tan minucuosamente comprendida. Se nos habla de vendedores de té, carniceros, monarcas, abuelas, obispos, policías y ciegos, sobre holgazanes, saladores y peluqueros, pero también sobre el Pont Neuf, la Sorbona, los mercados, Port Royal o Saint-Sulpice. Se nos llevara a los cafés y a los teatros, a plazas públicas, a puentes, carnicerías y disecciones, se nos habla de melones y muebles, chimeneas y vestidos, bastones, balcones, sombreos y puestos de coches, de pan de patata y carteles. En ligeros bosquejos se diseña una fenomenología de la ciudad cada vez más sorprendente, que no deja nada de lado, ni oficio, ni tipo, ni escenario, ni objeto alguno» (1986, págs. 82-83).

Los apuntes que Mercier bosqueja en cada capítulo son los detalles urbanos, las «costumbres», que en su conjunto ofrecen la fisonomía moral de la ciudad. Para Robert Barroux (1960, pág. 644) el éxito de Mecier consiste en que, paseando por París sin saber exactamente a dónde va, fija definitivamente la imagen de la gran ciudad al ofrecer las observaciones espontáneas de un transeúnte que la recorre de un extremo a otro, con lo que consagra la literatura del callejeo, la «flậnerie». El «flậneur» (Benjamin 1980, pág. 49) es el personaje de la ciudad, héroe de la modernidad, a cuya mirada se acomoda la pintura costumbrista y panorámica del mundo urbano que en la primera mitad del siglo XIX ofrecen libros como Le livre des Cent-et-Un, Les Français peints par eux-mêmes, Le diable à Paris, La grande ville (Lacombe 1887) y que llega al Baudelaire de los «Tableaux parisiens» (Stierle 1974). En España, basta citar el Panorama 
Matritense de Mesonero Romanos. Vemos cómo, con los antecedentes del XVIII \{Froldi 1996), la literatura de la ciudad se desarrolla en el XIX, primero en el costumbrismo y luego en la novela.

\section{Las horas de la ciudad}

La ciudad es espacio en sus aspectos topográficos, urbanísticos y monumentales, pero lo que le da vida es el tiempo que transcurre en ella. «Je vais parler de Paris --dice Mercier al comenzar su Préface-, no de ses édifices, des ses temples, de ses monuments, de ses curiosités, etc., assez d'autres ont écrit là-dessus. Je parlerai des mœurs publiques et particulères, des idées régnantes, de la situation actuelle des esprits, de tout ce qui m'a frappé dans ces amas bizarres de costumes folles ou raisonnables; mais toujours changeantes» (I, p. V). ${ }^{2}$ Lo que importa son las vivencias urbanas que marcan en sus contrastes lo que llama «la physionomie morale» de la ciudad.

Esta poética de la ciudad fomentada por la nueva mímesis es la que inspira el tema costumbrista del transcurso de las horas en un espacio urbano a lo largo del día. Lo encontramos inicialmente en el capítulo del Tableau de Paris titulado «Les heures du jour» (II, págs. 201-207) en el que se nos refiere el paso cotidiano del tiempo en diferentes escenas urbanas que ocurren en horas sucesivas. Es la visión panorámica de la ciudad a lo largo de un día, en un relato diacrónico de las actividades urbanas que pasan en París sucediéndose unas a otras. Comienza Mercier anunciando el desarrollo de ese proceso de la cronología cotidiana: «Les différents heures du jour offrent tour-à-tour, au milieu d'un tourbillon bruyant et rapide, la tranquilité et le mouvement. Ce sont des scenes mouvantes et périodiques, séparés par des temps à peu près égaux.» (II, pág. 201).

Es un tema que a partir de Mercier se va a hacer recurrente del XVIII al XX en la literatura costumbrista de la ciudad, digamos, de Louis-Sébastien Mercier a Ramón Gómez de la Serna pasando por Etienne Jouy, Charles Dickens, un artículo anónimo del Correo literario y mercantil que vamos a reproducir aquí y Ramón Mesonero Romanos, por lo que yo he podido averiguar, pero no me extrañaría que alguien añadiera algún otro eslabón en esta cadena. Naturalmente, cada autor aplica el recuso literario a su propia mirada. Aquí va mi lista:

Louis-Sébastien Mercier, «Les heures du jour», Tableau de Paris, Londres, 1781 .

2 Cito por la primera edición anónima de Londres 1781. En los años siguientes se hicieron en Amsterdam varias ediciones, también anónimas, corregidas y aumentadas hasta alcanzar los doce tomos de 1783 a 1788 . Hay edición moderna dirigida por Jean-Claude Bonnet, en dos tomos, Paris, Mercure de France, 1994. 
Etienne Jouy, «Paris a différentes heures», Paris, L'Hermite de la Chaussé d'Antin, Paris, 14 de marzo de 1913.

Anónimo, «XXIV horas de Madrid», Correo Literario y Mercantil, Madrid, 3 y 6 de diciembre de 1830.

Ramón de Mesonero Romanos, «Un día de Madrid», Manual de Madrid: descripción de la Corte y de la Villa..Reproducido en Cartas Españolas, III, Madrid, 1831.

Charles Dickens, «The Streets-Morning». «The Streets-Night», Sketches by Boz, Londres, 1833-1836.

Ramón Gómez de la Serna, «Algunas horas en la Puerta del Sol», Elucidario de Madrid, Madrid, 1931.3

\section{Literatura de la ciudad: del Correo literario y mercantil a las Cartas Españolas}

Aquí vamos a señalar cómo este tema costumbrista de las horas del día en la ciudad, iniciado por Mercier y tratado luego también por Jouy, se manifiesta en la prensa madrileña en el proceso de formación de la literatura de costumbres en el siglo XIX. Es bien sabido que esta nueva literatura se instituye en la prensa periódica madrileña a finales de la llamada «ominosa década», fomentada por el periodista José María de Carnerero en tres periódicos que él dirige sucesivamente, el Correo literario y mercantil (1828), Cartas Españolas (1831) y luego, la Revista Española (1832). Ya hace años, en un artículo de la Hispanic Review (Escobar 1977) ${ }^{4}$ mostré cómo el plan adoptado con gran éxito por Mesonero, en la segunda de las publicaciones citadas y continuado en la siguiente, de representar las costumbres urbanas de Madrid inspirándose en los cuadros de costumbres ciudadanas parisienses de Mercier y de Jouy, ya había sido intentado en la primera, el Correo literario y mercantil, sin que llegara a cuajar del todo. Hice ver cómo en un artículo de este periódico, con el título significativo de «Costumbres de

${ }^{3}$ Me gustaría añadir a la lista un reportaje de Antonio Jiménez Barca, publicado en El Pais del 6 de febrero de 2005, titulado «¿Qué pasaría si Madrid se quedara sin inmigrantes?», que a mi me ha Ilamado la atención porque muestra las vigencia del esquema costumbrista de las horas de la ciudad para describir la vida cotidiana del Madird de nuestros días. El periodista aplica el esquema inaugurado por Mercier y adoptado entre otros por Mesonero Romanos para señalar en sucesivas horas del día lo que ocurriría en la ciudad si no hubiera inmigrantes, a las tres de la mañana, a las siete, a las ocho, a las diez, a mediodía, a las tres de la tarde, a las cinco, a medianoche. Escrito con mímesis costumbrista nos ofrece escenas matritenses con la intenión «de reconstruir una hipotética jornada de caos. La de un día laborable sin inmigrantes».

${ }^{4}$ En las últimas décadas se ha realizado una revalorización crítica del costumbrismo como movimiento renovador de la literatura moderna desde el siglo XVIII. Ahora intento poner al día mis propios trabajos teniendo en cuanta las contribuciones de esta crítica renovadora. 
Madrid» ( 8 de agosto de 1828), basado directamente en el «Préface» de Mercier al Tableau de Paris, y bajo la férula de Carnerero, se ofrecía el proyecto de pintar la vida ciudadana de Madrid: «Intentamos presentar al público algunos cuadros de las costumbres de la capital de las Españas». Por lo que leemos en este artículo programático, el Correo tiene la intención de publicar una serie cuadros de costumbres que ofrezcan una imagen de Madrid, pero evitando, como había hecho el modelo francés, los aspectos topográficos y arqueológicos -esto lo "podrán ver los curiosos en los tomos del Viaje del Sr, Ponz) - para pintar, en cambio, la realidad inmediata de la vida de la ciudad que trancurre ante la mirada de los vecinos y del periodista observador: «lo que todos estamos viendo». Por eso afirma: «Nuestros cuadros han de tener vida, porque han de ser el retrato de los habitantes, de sus costumbres públicas y de las particulares, de su clase, de sus vicios y de sus virtudes; en una palabra, de todo lo que nos ha llamado la atención a nosotros». Y añade que sus escritos han de hablar de lo que en la ciudad «pasa hoy, en el día en que escribimos y de las personas que nos rodean». Se declara, por lo tanto, una intención manifiesta de escribir la literatura de «lo que pasa entre nosotros» que había anunciado El Pensador el siglo anterior y que El Curioso Parlante anuncia al expresar, en su primer artículo de la Revista Española, el propósito de «consultar en mis discursos la impresión que en mí produjeron los objetos que me rodean» (Escobar 1977).

A los redactores costumbristas de las tres publicaciones periódicas de Carnerero, con menor o mayor éxito, les mueve el mismo propósito de escribir literatura de la ciudad, según el proyecto propuesto inicialmente por el Correo Literario y Mercantil, en 1828, de «nada menos que escribir Madrid, lo mismo que Mercier había escrito París en los umbrales de la Revolución francesa» (Baker 1991, 69 n.18) y lo mismo que luego había hecho Jouy después de la Revolución. Efectivamente, los modelos reconocidos son los dos costumbristas franceses: «no tenemos por despreciable un trabajo, que han creído digno de su pluma los Mercier y los Jouy; y que nos contentaríamos con saber imitar a cualquiera de los dos, como lo intentaremos», leemos en el artículo del Correo. Como ellos habían instituido a París protagonista de su literatura de la ciudad, el redactor del Correo expresa su intención de hacer lo mismo con Madrid. Con ello abre la senda que va a caminar El Curioso Parlante con excelentes resultados en el periódico siguiente, Cartas Española, en que se publica la serie del Panorama Matritense, también bajo la misma férula de Carnerero. Al afirmar el protagonismo de Madrid en sus cuadros de costumbres, Mesonero, como el redactor del Correo, y antes Mercier con respecto a París, insistirá en la diferencia entre el «Madrid físico» que realiza en el Manual de Madrid y el «Madrid moral» en el Panorama Matritense (Escobar 1977, pág. 36; Baker 1969, págs. IV-V y 1991, págs. 61-62), para él pespectivas difrentes, pero complementarias de un mismo conjunto urbano. Este 
protagonismo de Madrid en la obra de Mesonero culminará con sus Memorias de un setentón en que, como dice Fernando Durán López (2000-2001, pág. 57), el memorialista vincula «la memoria a un espacio geográfico concreto [Madrid], presente en el relato como protagonista, no sólo como escenario»..$^{5}$

Sin duda, será Mesonero Romanos, cuando ya se acerca la transición política, el periodista que va a realizar con pleno éxito en las Cartas Españolas y en la Revista Española, lo que Carnerero se había propuesto iniciar en su periódico anterior en plena época absolutista, es decir, en circunstancias políticas y culturales menos favorables para que el proyecto pudiera madurar. Como señala Edward Baker, deben de tenerse en cuenta las diferencias entre las circunstancias históricas en que escriben los redactores a los que Carnerero encomienda la tarea periodística de escribir sobre las costumbres de la población madrileña, ya que «entre el propósito que en 1828 tenían los redactores del Correo Literario y Mercantil... y lo realizado por Mesonero en las Cartas Españolas en 1832 y 1833, hay dos situaciones históricas distintas, la una fundamentalmente inmovilista, y la otra de pretransición» $(1991,69$, n. 18). A diferencia de los redactores del raquítico Correo, Mesonero Romanos, con ideología burguesa (Kirkparick 1978), escribe, en cambio, en una revista mucho más moderna, de más fuste, Cartas Españolas, lanzada por Carnerero cuando, como señala dicho crítico, en el «mundo, política y culturalmente miserabilizado del absolutismo agonizante, empieza a perfilarse hacia 1832 un modesto y más que modesto relanzamiento de la actividad literaria y cultural madrileña, centrada en buena medida en la leve pero importante recuperación de la prensa periódica». En la transición del antiguo al nuevo régimen, el impulso ideológico que inspira la literatura de Mesonero Romanos es, «en resumidas cuentas, la nacionalización simbólica del espacio urbano» (Baker 1989, pág. XIX), al tratar de extender la significación de Madrid, convirtiendo la capital en símbolo nacional de la clase social que él representa. Ermanno Caldera (1964, pág. 103) advierte que pese a que Mesonero «no participara en política de un modo activo y militante, no obstante es lógico pensar que sería algo más que un simple espectador, aunque de primera fila, como quiere definirse. Su posición social, las funciones cada vez más oficiales que sucesivamnete desemepeña, también en sectores necesariamente conectados con la actividad política, en fin su amor por España le impedian un efectivo arrinconamiento en las confrontaciones de vida pública». Entre estas funciones oficiales destaca el cargo de concejal del Ayuntamiento de Madrid. Su supuesta neutralidad política no impide una visión ideológica de la realidad social propia de su clase que impregna la imagen de la

${ }^{5}$ Durán remite en esto a James D. Fenández $(1992,106)$, continuador de Edward Baker (1989 y 1991) en decir que Mesonero «escribe Madrid». Como hemos visto, Baker también reconoce que éste era el propósito de los redactores del Correo Literario y Mercantil en 1828 
vida urbana que escribe. ${ }^{6}$ Como hace ver Susan Kirpatrick, Mesonero identifica nación con clase media, mientras que Baker añade Madrid a esta identificación nacionalista. Éste es, al fin y al cabo, el Madrid que intenta «escribir» el Correo, el que «escribe»-crea-Mesonero y que luego será «materia novelable».

Entre los artículos de costumbres de Madrid que aparecen en el Correo, Evaristo Correa y Calderón destaca el firmado por El Obsevador con el título de «Una casa en el barrio de las Platerías» (núm. 48, 31-10-1828) que incluye en su monumental antología de Costumbristas españoles (I, 1950, págs. 680-682), atribuyéndolo erroneamente a Mariano de Rementería y Fica (Escobar 1970) que sustituyó a Carnerero en la dirección del periódico cuando éste lo dejó para fundar las Cartas Españolas en marzo de 1831. Correa Calderón considera el artículo de El Observador como un «abigarrado desfile de vecinos de una casa madrileña, que pudiera considerarrse germen de las escena que más tarde pintará Mesonero Romanos» (I, 1950, pág. XXIII) Ya expliqué en otro lugar (Escobar 1976) las conexiones que unían el artículo de 1828, del Observador, y el de 1832, «Las casas por dentro», del Curioso Parlante, como muestras significativas de lo que venimos llamando «literatura de la ciudad», de «lo que pasa entre nosotros».

\section{Las horas de la ciudad en el Correo y en las Cartas Españolas}

Otro artículo del Correo que se relaciona igualmente con Mesonero Romanos es titulado «Las XXIV horas de Madrid», publicado sin firma, en dos núneros del periódico, múm. 375 y 376, del 3 y 6 de diciembre de 1830, que hemos incluido en la lista anterior de textos sobre el tema de las horas de la ciudad y que reproducimos en apéndice. El cuadro de las horas de la ciudad se sitúa en la línea de los cuadros de costumbres que venían apareciendo en el periódico de Carnerero desde 1828, a raíz del referido artículo programático «Costumbres de Madrid». Así como «Una casa en el barrio de las Platerías» pretendía pintar la vida de los vecinos de una casa madrileña siguiendo el modelo de Jouy en «Les six étages d'une maison de la rue Saint-Honoré» (II, págs. 133-145), el autor de «Las XXIV horas de Madrid» aplica el esquema de Mercier en el citado capítulo del Tableau de Paris «La heures du jour» y de Jouy en «Paris a différentes heures» (III, págs. 129-138) para mostrar lo que pasa en Madrid durante todo un día de hora en hora.

${ }^{\circ}$ Mesonero Romanos suscitó la réplica anónima de un libro titulado ;Madrid! Indicaciones de una española española (Madrid, Eusebio Aguado, 1833) en que se critica su Manual de Madrid desde una ideología propia del Antiguo Régimen, defensora del Altar y el Trono. María de los Ángeles Ayala $(1999,92)$ resume así la el pensamiento reaccionario de esta réplica: «La Iglesia unida a la monarquía borbónica será el bastión indeleble de las costumbres patrias, inmersas en su tradicionalismo y en contra de la corrupción moral proveniente del extranjero»». 
La relación de este cuadro de costumbres del Correo con Mesonero Romanos queda de manifiesto en la reseña de su Manual de Madrid: descripción de la Corte $y$ de la Villa, publicado en octubre de 1831, que José María de Carnerero inserta en sus Cartas Españolas (III, 26, 22 de noviembre de 1831, págs. 168-174). A pesar de la «multitud de conocimientos topográficos» que Carnerero destaca en la obra de Mesonero y reseña con admiración y detenimiento como principal aportación de la obra que comenta, cuando quiere dar un ejemplo de cómo la mirada del autor capta la ciudad, la muestra que escoge no es un visión del Madrid físico que aporta el Manual, sino un cuadro de la fisonomía moral de la Capital, «Un día en Madrid», semejante a la que El Observador había ofrecido a los lectores de Correo Literario y Mercantil meses antes en el artículo «Las XXIV horas de Madrid».

El director de la revista escribe la reseña como carta de contestación adjunta al envío del libro de Mesonero que le ha encargado «un amigo residente en provincia, dándole cuenta de la obra publicada por don Ramón de Mesonero Romanos». Carnerero empieza la carta resaltando la utilidad práctica de la obra por la abundancia de sus «conocimientos topográficos». El Madrid que Mesonero ofrece a la imaginación del lector le sugiere al crítico el símil óptico de la ciudad como prisma con que trata de captar sus aspectos cambiantes: «Comparable a un prisma, una ciudad populosa recibe tantos cambios en multitud de objetos, que muchas descripciones exactas hoy dejan de serlo mañana»y.

En el apéndice a la reseña epistolar, Carnerero reproduce el texto que Mesonero titula «Cuadro de un día en Madrid» en el epígrafe del capítulo II del Manual. No vamos a transcribir aquí el texto de Mesonero que es fácilmente accesible (Mesonero 1967, págs. 24-25, y 1990, págs. 60-64). A cualquier lector que lea «Las XXIV horas de Madrid» y «Un día en Madrid,» impresos con poco tiempo de diferencia en el Correo Literario Mercantil y en las Cartas Españolas respectivamente, le llamará la atención la semejanza de los títulos que indica la coincidencia en la actitud con que sus respectivos autores miran la ciudad a lo largo del día, aunque no coincidan en todo lo que uno y otro ven a cada hora. Los dos textos se escriben más a menos al mismo tiempo. Como hemos dicho, el artículo del Correo es de diciembre de 1830 y en septiembre de 1831 Mesonero entrega a los reyes los dos primeros ejemplares del Manual (Romero Tobar 1974). Según dice el autor, el proyecto de la obra se inicia cuatro años antes, cuando empieza a recoger materiales (Sarrailh 1925), por lo que pudo leer el artículo del Correo, del que él era colaborador por aquellos años, ${ }^{7}$ mientras redactaba el Manual.

${ }^{7}$ Enrique Rubio Cremades (1995, 22 n. 26) señala las colaboraciones de Mesonero durante los años 1828 y 1829 y el 14 de febrero de 1831 publica una crítica del drama de Hartezbush Las hijas de Gracián Ramirez, o la Restauración de Madrid 
Como Mercier y Jouy habian observado la sociedad de París a varias horas del día, tanto el redactor del Correo como Mesonero Romanos en sus cuadros nos presentan la vida urbana de Madrid desde la mañana a la noche. Los dos empiezan al amanecer observando cómo las puertas de Madrid se abren «para dar entrada a la infinidad de aldeanos que conducen las producciones de sus lugares circunvecinos para depositarlas en los abundantes mercados de la capital» al decir de Mesonero Romanos en un párrafo inicial que coincide con lo que había observado el periodista del Correo a las cinco de la mañana en que «se acercan a las puertas de Madrid los tragineros y todos los que conducen comestibles frescos, que entran por la puerta de Toledo, excepto la tropa de hueveras que atraviesa con sus borricas por la puerta de los Pozos». ${ }^{8}$

Los dos concluyen con una visión inmovilista de la fisonomía de la ciudad, de tiempo circular: al día siguiente todas las horas se repiten, todo sigue igual. Todo «viene en el fondo a ser lo mismo por lo que toca a los usos y costumbres», según el redactor del Correo, y Mesonero, para concluir «Un día en Madrid,» nos dice: «y el cuadro anterior vuelve a comenzar».

La última hora del artículo de 1830 es así:

Las cuatro. Retíranse los serenos y los carros de Sabattini, que tropiezan en el camino con los enormes serones de los caballos del pan, y con tal cual trapero, que madruga por si puede encontrar alguna prenda perdida la noche anterior en los parajes públicos del Prado, Puerta del Sol y puertas de los teatros y de las iglesias.

Tal es el plan distributivo de las veinticuatro horas de Madrid, el cual, si bien varía según la estación del año, viene siempre en el fondo a ser lo mismo por lo que toca a los usos y costumbres que acaban de describirse y que pueden servir para dar a los extranjeros una idea de la fisonomía de esta capital.

Mesonero obseva cómo avanza la noche:

La multitud va disminuyendo en las calles; los barrios apartados permanecen solitarios, y sólo los del centro ofrecen todavía vida hasta después de cerrados los teatros. La mayor parte vuelve a su casas a disfrutar del reposo; pero otra parte prolonga la vida que hurtaron al día, ostentando en tertulias elegantes sus estudiados adornos, o arruinándose en juegos reprobados; sus coches hacen retemblar las pacificas calles, y va disminuyendo su número hasta que ya a las dos de la mañana se oye solo la voz del vigilante sereno, que da la hora y avisa al desvelado las que aún le faltan que penar. Los cantos de las aves precusoras del día suceden a aquel silencio, y el cuadro anterior vuelve a comenzar.

\& De París, dice Mercier: «A une heure du matin, dix mille paysans arrivent, portanr la provision de légumes, du fruit et des fleurs. Ils s'acheminent vers la Halle: leurs montures sont lasses et fatigués; ils viennent de sept à huit lieues» (II, 204). 


\section{Las horas de la ciudad en ;Madrid! Indicaciones de una española}

Al cuadro «Un día en Madrid» le dedica un comentario la réplica de 1833 al Manual de Madrid, titulada ;Madrid! Indicaciones de una española (págs. 93-96). Nos interesa este comentario sobre todo porque es un texto contemporáneo de Mesonero Romanos que ya vincula directamente el texto de «Un día en Madrid» de su Manual de Madrid con «Les heures du jour» del Tableau de Paris, de Mercier, poniendo así el cuadro de Mesonero en la línea de la la literatura de la ciudad a la que pertenece, según ha puesto de manifiesto la actual crítica comparatista del costumbrismo. Sin nombrar el título ni el autor del libro francés, equipara la obra de Mesonero con la de Mercier («en otro libro algo parecido al Manual», pág. 95), advirtiendo al lector de que el autor madrileño, en contra de lo que hace el del Tableau de Paris, no se atreve a referir situaciones escabrosas que ocurren en su ciudad como ocurren en París. Según las indicaciones de la española, de Madrid podrían contarse «inmoralidades y miserias presentes» semejantes a las que refiere Mercier de París sobre las prostitutas y tahúres, pero que Mesonero deja fuera de su cuadro: «Por miedo ni miramientos no habrá sin duda dejado de describir muchas de las cosazas que suceden a menudo, y otras diariamente a horas fijas» (pág. 93). La indicaciones de la española contienen la traducción de fragmentos del capítulo «Les heurs du jour» del Tableau de Paris para colmar el incompleto cuadro madrileño de Mesonero con lo que éste deja de pintar y que la autora de la réplica echa de menos:

En otro libro algo parecido al Manual he leído en el artículo horas del día... Esta es también la hora, en la cual multitud de prostitutas te persiguen... dicen que la incontinencia sirve de defensa a la castidad; que estas mujeres viles preservan la honra de las doncellas honesta (pág. 95$)^{10}$

La supuesta española anónima, autora de ;Madrid!, comenta a esto:

Será; pero más cierto es que semejantes diabluras, do quiera que ocurran, conviene exorcismarlas.

Luego sigue traduciendo de «Les heures du jour» lo que, según ella, también podría decirse de Madrid:

Véase n. 5.

10 Mercier había escrito, en efecto, con más detalle, lo que ocurría a las nueve de la noche en Paris: «C'est l'heure aussi où toutes les prostituées, la gorge découverte, la tête haute, le visage enluminé, l'œil aussi hardi que le bras, malgré les lumiers des boutiques et des réverbers, vous poursivent dans les boues, en bas de foie et en souliers plats: leus propos répondent à leurs gestes. On dit que l'incontinence sert á préserver la chasteté; que ces femmes vulgivagues empêchent le viol; que sans les filles de joie, on se seroit moins de scrupule de séduir et d'enlever de jeunes innocentes»y (II, 203). 
Al amanecer salen de ciertas casas varios libertinos pálidos, desfigurados, trémulos, con el sello del temor en los rostros, donde debiera aparecer el de los remordimientos. Algunos no dejarán de verse pesarosos durante todo el día de sus ocupaciones nocturnas; pero el hábito a la disolución, cual un tirano se apoderará de ellos la siguiente noche, y les conducirá con paso lento al sepulcro. Los jugadores salen también en aquellos momentos de sus ilustres o viles gazapones, se les ve a unos descompuestos y macilentos, aporreándose y escupiendo al cielo; otros deseando volver cuanto antes al tapete que le ha favorecido, sin pensar siquiera que puede burlar sus deseos. ${ }^{11}$

Y la «española» añade una nota entre paréntesis: «Nota bene: esto no se dijo de España, pero podía» (pág. 96).

\section{Conclusión. «Un día en Madrid», primer cuadro de costumbres de Mesonero Romanos}

La relación establecida por las Indicaciones de una española entre el texto del Manual de Madrid y el del Tableau de Paris, podría heberse hecho también con el anónimo del Correo Literario y Mercantil. Estas relaciones vienen a confirmar la ya sabida filiación textual dieciochesca del costumbrismo decimonónico madrileño que se establece en la prensa periódica en los años finales del antiguo régimen y en la trasición al nuevo; es decir, la filiación con la literatura europea de la ciudad que se inciacia en el XVIII con la poética promovida por la concepción moderna de la mímesis literaria.

La proximidad en los dos periódicos de Carnerero entre los cuadros «Las XXIV horas de Madrid» de 1830 y «Un día en Madrid» de 1831, cuyo primer antecedente es «Les heures du jour», muestra una vez más la continuidad de una publicación a otra en la formación del nuevo costumbrismo que se consagra en el Panorama Matritense cuyos cuadros pretendía Mesonero ofrecer como inicio del nuevo género en la literatura española, reconociendo el modelo de escritores modernos ingleses y franceses, pero con mirada madrileña. Si el artículo «Una casa en el barrio de la Platerías» es una muestra de esa adaptación madrileña del género que va a culminar en el Panorama Matritense, del mismo modo lo es «XXIV horas de Madrid» que también encuentra la réplica en la representación de la vida de la ciudad que pretende realizar Mesonero en sus cuadros de costum-

${ }^{11}$ Le matin, les libertins sortent de chez les filles publiques, pâles, défaits, emportant la crainte plutôt que le remord; et ils gémiront tout le jour de l'emploi de la nuit: mais le débauche ou l'habitude est un tyran qui les saisira le lendemain, et qui les traînera à pas lents vers le tombeau.

Les joueurs plus pâles encore sortent des tripots obscurs et renommés; les uns se frappent la tête et l'estomac, jettant au ciel des regards désespérés; les autres se promettant de revenir à la table qui les a favorisés, mais qui doit les trahir le lendemain (II, 206). 
bres. Su cuadro «Un día en Madrid», representación de la vida cotidiana de la población, destaca en medio de la topografía de la Capital por su dimensión moral propia de la concepción literaria de la mímesis costumbrista, por lo que podemos considerarlo del mismo género literario que los cuadros de costumbres de lo que va a ser el Panorama Matritense en las Cartas Españolas de Carnerero. En realidad, tiene más afinidad textual con esta serie que con el conjunto del Manual en que se incluye. Que el director de la revista inserte «Un día en Madrid» en su revista, como texto independiente, separado del resto topográfico del Manual de Madrid, lo confirma. Es un modo de constituir implícitamente ese texto en el primer cuadro de costumbres de la serie del Curioso Parlante que, bajo su dirección, va a seguir en la misma revista con el titulo de Panorama Matritense con la intención crear la imagen literaria de la ciudad, realizando la pintura del «Madrid moral» con una perpectiva diferente, pero complementaria del «Madrid físico» ofrecido en el Manual de Madrid, como ya se ha indicado.

\section{APÉNDICE}

\section{Las XXIV horas de Madrid}

(Este artículo se escribió en el mes de abril y su descripción es análoga a dicha época del año y a todas con corta diferencia.)

A las cinco de la mañana se oye el toque de Diana en los cuarteles y se acercan a las puertas de Madrid los tragineros y todos los que conducen comestibles frescos, que entran por la puerta de Toledo, excepto la inmensa tropa de hueveras que atraviesa con sus borricas por la puerta de los Pozos. Empiezan a formarse en la tela del puente en prolongadas hileras las carretas de carbón, que suben pausadamente por la calle de Segovia al compás del crujido de las ruedas y de las voces que dan a los bueyes sus andrajosos conductores.

A las seis abren los comerciantes sus tiendas y ya están trabajando jornaleros y menestrales, mientras duermen profundamente los jugadores, busconas y lechuguinos de profesión. Los arrieros de frutas y verduras venden por mayor su mercadería y empieza la algarabía de las vendedoras y el ajuste y regateo de los mozos de compra. Esta es hora menguada para los cabezas de casas y lucrativa para los mayordomos y abastecedores de ellas. Entre las criadas vizcainas que van a la plaza se ve tal cual pisaverde en deshabillé en busca de carne fresca.

Siete de la mañana. Hora aciaga para los estudiantes y modistas porque éstas empiezan su labor en sus respectivos talleres de la calle de la Montera y aquéllos su estudio en las diferentes aulas a que asisten. Pónense en movimiento todos los molinillos de Madrid: sírvese el chocolate y se lee al mismo tiempo el Correo literario y mercantil y el Diario de Avisos. 
A las ocho se dirigen al palacio de los duques de Uceda los consejeros precedidos de los escribanos de cámara, relatores y demás depedientes suyos, acompañados todos por el marcial ruido de las cajas de las guardias entrantes y salientes. A esta hora, poco antes o poco después, se administra en las parroquias el sacramento del matrimonio. Los barberos van y vienen cargados con sus instrumentos y con mil noticias y mentiras de diversas clases para repartirlas según los gustos e intereses de sus parroquianos mientras dura la operación de la barba.

Las nueve. Se nota aumento en la afluencia de gentes y en el movimiento de las personas: se dirigen mustios a sus oficinas los empleados de las subalternas, pues los de las superiores acuden unos a las diez y otros a las once. Se derraman los carteros desde el centro de la Puerta del Sol hasta los puntos más distantes de la población, llevando consigo el consuelo de unos y la desesperación de otros: los efectos que van produciendo los carteros en su curso son semejantes a los del juego del monte: una misma carta y un mismo hombre dan alegría a unos y hacen la desventura de otros. Abogados de golilla que acuden unos en coche y otros a pie a defender en estrados la causa de sus clientes. Los desocupados de todas clases hacen círculo alrededor de la gran música de la guardia de relevo que va a las nueve a palacio.

Las diez. A esta hora crecen los gritos de las hueveras foncarraleras, lecheras y demás forasteros que desean rematar sus mercaderías para volver a sus hogares. Empiezan a rebullir entre las sábanas de holanda los que roban al sol todo lo que dan a la disipación en la última época de la noche. En el despacho de billetes para la ópera, aprietos, contusiones y aun manotadas entre los candidatos entre sí: esta es la hora feliz de los expendedores de los billetes.

Las once. Esta es la época de la segunda comida que hacen los habitantes de Madrid conocida con el nombre de almuerzo, a diferencia de la anterior que se llama el chocolate. Salen de sus casas los petimetres y empleados de alto bordo; aquéllos a galantear o a matar el tiempo y éstos a trabajar en sus oficinas hasta más de las tres de la tarde: algunos de éstos van en coches que conducen a palacio grandes uniformes los jueves y domingos de corte y los días de gala.

Las doce. Se da audiencia al público en muchas oficinas... Bullen curiales y litigantes en la Villa y en la cárcel de Corte...Afluencia de procuradores, escribanos de diligencias y litigantes en el edificio de los Consejos: notificanse las sentencias y se hinchan prodigiosamente las bolsas de los curiales. Salen los consejeros. Dejan también sus labores los abogados, los hombres laboriosos e independientes y los albañiles. Las campanas anuncian que es el momento de que los fieles eleven al Señor la plegaria del medio día. El coche de los teatros, grande en peso y en capacidad, tirado por dos caballos consuntos, conduce solemne y pausadamente a las cómicas: acuden a pie los galanes por distintos caminos para celebrar el ensayo y se entabla y fomenta la chismografía de bastidor. Los infe- 
lices condenados a la última pena son conducidos a la plazuela de la Cebada en medio de un inmenso populacho y pagan en el patíbulo la deuda de sus crímenes; la campana de $\mathrm{S}$. Millán aterroriza al malvado y arranca una lágrima de compasión al hombre sensible y virtuoso.

La una. A esta hora comen los pobres y entonces mismo concluyen su tocador las damas de gran tono para recibir las visitas llamadas de cumplimiento, que el uso y la etiqueta colocan en esta hora. Salen las modistas de sus talleres y se encuentran casualmente con sus amigos y apasionados: el camino que llevan aquellas a sus casas suele no ser el más corto; pero siempre es el más divertido.

La una y media. Se reúnen los corredores en la lonja de comercio a fijar el curso del papel y de los cambios, que se publica luego en un boletín impreso.

Las dos. Movimiento general de las mandíbulas, que no cesa en Madrid hasta más de las cinco, pues según las diversas clases de los habitantes empiezan unos cuando acaban otros. Se retira la numerosa hueste de empleados, inundando las calles cercanas a la casa de Consejos y a la aduana: al paso se proveen aquellos de frutas para que les sirvan de postres y las van conduciendo ciudadosamente en sus pañuelos. Los días festivos es la gran concurriencia en la Puerta del Sol para oír la misa de dos en el Buen Suceso, que por falta de sitio oyen algunos desde la calle.

Las tres. Se despiden de las tiendas de la calle de la Montera para irse a comer los lechuguinos y al mismo tiempo se disparan de las neverías los horchateros, pregonando y vendiendo unos productos fríos y blanquinosos que ellos llaman helada de chufas.

Las cuatro. Empieza el silencio de la siesta en el verano y en el invierno la hora de paseo. Los lunes de toros se puebla de personas y calesines la calle de Alcalá, todos con dirección a la plaza que está fuera de la puerta de este nombre.

Las cinco. Concurrencia en los cafés, no de señoras como al anochecer, sino sólo de hombres de la clase acomodada, en donde se habla magistralmente de política, de cómicos y de toreros, de literatura y de chismografía universal. Los lunes a esta hora en la plaza de toros, bulla, gritos, abanicos, naranjas y calor, todo reunido.

Las seis. Principia el movimiento de los coches y de las personas que van al Retiro y al Prado: reúnense luego en este último los paseantes del estanque del Retiro y demás sitios vecinos: en el salón se pasean personas; al lado caballos y cocheros; allí se oyen requiebros, disputas, saludos; aquí solo el relinchar de los caballos y el crujir de los carruajes; dentro de ellos van las personas; la calle que media entre el salón y los coches la ocupan los que quieren hacerse remarcables.

Las siete. Discurren en todas direcciones los serenos con escaleras y mechas ardiendo y en muy pocos minutos quedan encendidos todos los faroles que for- 
man el alumbrado de Madrid. Grande peligro de ser atropellado en las calles del Príncipe y de la Cruz por los torpes cocheros que conducen a sus señores al teatro. A esta hora (o mejor dicho al anochecer, que varía según las estaciones) salen los trabajadores y se verifica la mayor concurrencia en todas las calles de la corte, que crece en las que son más generalmente frecuentadas.

Las ocho. Siguen al anochecer los entierros que se celebran en las iglesias parroquiales a la hora que los bautismos. Tal vez los mismos que tristes imploran del Altísimo el eterno descanso del difunto, asistieron a la misma hora y en el mismo lugar a la acción de gracias que celebra la Iglesia cuando sienta en sus registros un cristiano más. Las bandas de música conocidas con el nombre de murgas felicitan con sus instrumentos de viento a los ricos que acaban de llegar a la corte, a los que han recibido algún nuevo empleo de honra o provecho y por último atruenan las puertas de los que tienen el nombre del santo que se celebra el día siguiente. Llénanse de concurrentes los cafés y se agotan todos los helados y bebidas, señaladamente en los que están cercanos al Prado y en las acreditadas botillerías de la calle de Carreteras y de S. Antonio de los Portugueses.

Las nueve. $\mathrm{Al}$ dar en el reloj del Buen Suceso rompen las retretas y se dirigen las bandas a sus respectivos cuarteles. Esta es la hora en que empiezan las funciones caseras de bailes, conciertos y demás. Estos saraos exigirían por sí solos un artículo particular, que se omite porque no es de este lugar detenerse en las particularidades interiores de Madrid.

Las diez. A esta hora empiezan las tertulias de más etiqueta: entre ellas las hay muy respetables, en donde reina la urbanidad, el decoro y el inocente placer de la sociabilidad o el de los juegos honestos; pero hay otras en donde se reúnen los concurrentes con el honesto fin de quitarse el dinero unos a otros. A esta hora circulan ya los ejemplares de la gaceta del día siguiente entre el público de suscriptores.

Las once. Se establecen los serenos en sus barriadas y dan cuenta de su presencia a los vecinos por medio de sus desagradables entonaciones. Se retiran los coches del teatro con inusitada velocidad, en sumo grado peligrosa para los que transitan a pie. El ruido de los carruajes concierta con el que hacen las tiendas al cerrarse.

Las doce. Empieza el servicio del tren inventado por el célebre Sabattini, cuyos carros tienen, no sé por qué, un sonido tan particularmente penetrante que se los percibe a muy larga distancia, aún sin hacer uso del sentido del olfato. En los intervalos de este ruido infernal se oyen las companas que tocan a maitines en los conventos de religiosos de uno y otro sexo.

La una. Silencio general, sólo turbado por el comadrón que acude a alguna parturienta o por la indicación de las horas vociferadas por los soñolientos serenos. Los usureros y los enamorados velan todavía: aquéllos para contar y recontar 
su dinero y asegurarse después de la cerradura y éstos para pensar en su Dulcinea y llorar los desdenes o celebrar los triunfos del día. Acompáñalos algún poeta que busca las consonantes a la escasa luz de una vela de sebo, que brilla como estrella del firmamento en lo más empinado de una guardilla.

Las dos. Sueño profundo. Esta es la ocasión de hacer el contrabando por las tapias o por las puertas de Madrid y también lo sería de que ejerciesen su vigilancia los celadores del alumbrado y de la limpieza. Hacen los panaderos sus amasijos, sus sisas y sus enjuages; humean los hornos y se prepara en ellos la cochura de los muchos miles de libras de pan que se consumen en Madrid diariamente.

Las tres. A esta hora dejan los naipes y se dirigen a sus casas los jugadores de oficio, opulentos unos y arruinados otros; pero todos amarillos y macilentos, murmurando a traspieses del ganarán, la mayor y la contra-judía. Velan todavía y trabajan y cantan los sastres las vísperas de las grandes fiestas.

Las cuatro. Retíranse los serenos y los carros de Sabattini, que tropiezen en el camino con los enormes serones de los caballos del pan y con tal cual trapero, que madruga por si puede encontrar alguna prenda perdida la noche anterior en los parajes públicos del Prado, Puerta del Sol y puertas de los teatros y de las iglesias.

Tal es el plan distributivo de las veinticuarto horas de Madrid, el cual, si bien varía según la estación del año, viene siempre en el fondo a ser lo mismo por lo que toca a los usos y costumbres que acaban de describirse y que pueden servir para dar a los extranjeros una idea de la fisonomía de esta capital.

Correo literario y mercantil, núms. 375 y 376, 3 y 6 de diciembre de 1830 . 


\section{BIBLIOGRAFÍA}

ÁlVAREZ BARRIENTOS, Joaquín, 1990. «Del pasado al presente. Sobre el cambio del concepto de imitación en el siglo XVIII español», NRFH, XXXVIII, págs. 219-245.

AYALA ARACIL, María Ángeles. « Madrid! Indicaciones de una española, réplica al Manual de Madrid de Mesonero Romanos», en Ideas en sus paisajes. Homenaje al profesor Russell P. Sebold, Alicante, Universidad de Alicante, 1999, págs. 91-96.

BAKER, Edward, 1989. Introđucción a Ramón Mesonero Romanos, Rápida ojeada sobre el estado de la Capital y los medios de mejorarla, Madrid, Cidur, Revista Alfoz.

- 1991. Materiales para escribir Madrid: literatura y espacio urbano de Moratín a Galdós, Madrid, Siglo Veintiuno.

BARROUX, Robert, 1960. «Sébastien Mercier le promeneur qui ne sait où il va», Mercure de France, CCCXXVIII, págs. 642-659.

Benjamin, Walter, 1980. Poesía y capitalismo. Iluminaciones II, trad. de Jesús Aguirre, Madrid, Taurus.

CALDERA, Ermanno, 1964. Il problema del vero nelle Escenas Matritenses, Miscellanea di Studi Ispanici, Pisa.

DuráN LóPEZ, Fernando, 2001-2002. «Las Memorias de un setentón de Mesonero Romanos en el marco de la autobiografía española decimonónica», A.L.E.U.A., 14, págs. 41-64.

Clavijo y Fajardo, José, 1762. El Pensador, por Don Joseph Alvarez y Valladares, I, Madrid, Ibarra

Correa CALderón, Evaristo, 1950-51. Costumbristas españoles: estudio preliminar y selección de textos, Madrid, Aguilar, 2 vols.

ESCOBAR, José, 1970. «Sobre la formación del artículo de costumbres: Mariano de Rementería y Fica, redactor del Correo literario y mercantil»), BRAE, L, págs. 559-573.

- 1973. Los origenes de la obra de Larra, Madrid, Prensa Española.

- 1976. «Un tema costumbrista: Las casas por dentro en L'Hermite de la Chaussée d'Antin, El Observador y El Curioso Parlante», REH, I, págs. 39-47.

- 1977. ««Costumbres de Madrid»: influencia de Mercier en un programa costumbrista de $1828 », H R$, XLV, págs. 29-42.

- 1988. «La mímesis costumbrista», KRQ, XXXV, págs. 261-270.

- 1994. «La literatura de «lo que pasa entre nosotros». La modernidad del costumbrismo», en B. Pallares, J. Peira y J. SÁnchez Lobato (eds.), Sin Fronteras. Homenaje a María Josefa Canellada, Madrid, Editorial Complutense, págs. 195-206. 
FERNÁNDEZ, James D., 1992. Apology to apostrophe: autobiography and the rhetoric of self-representation in Spain, Duke University Press.

Ferraz Martínez, Antonio, 2003. «Entre novela y teatro: El discurso de Mesonero Romanos sobre los artículos de costumbres en el marco de la transformación moderna del concepto de imitación», Rlit. LXV, págs. 85117.

FrolDI, Rinaldo, 1996. «Anticipaciones dieciochescas del costumbrismo romántico», Romanticismo 6, Roma, Bulzoni, págs. 163-169.

JouY, Étienne de, 1814-15. L'hermite de la Chaussée-d'Antin; ou, Observations sur les mceurs et les usages parisiens au commencement du 19e siècle, Paris, C. Pillet.

KIRKPATRICK, Susan, 1978. «The Ideology of Costumbrismo», I\&L, II, No. 2, págs. 28-44.

LACOMBE, Paul, 1887. Bibliographie parisienne, tableau de mours (1600-1880), Paris, Rouquette.

MARÚN, Gioconda, 1983. Origenes del costumbrismo ético-social. Addison y Steele: antecedentes del costumbrismo español y argentino, Miami, Ediciones Universal.

1984. ¡Madrid! Indicaciones de una española sobre inmoralidades y miserias presentes, y su renmedio. Facsímil de la edición de Madrid de 1833, Madrid, Méndez Editores.

MERCIER, Louis-Sébastien, 1781. Tableau de Paris, A Londres.

Mesonero Romanos, Ramón, 1967. Manual de Madrid, en Obras de don Ramón de Mesonero Romanos, III, Carlos SECo SERRANo (ed.), BAE, CCI, Madrid, Atlas.

- (1833) 1990. Manual de Madrid. Descripción de la Corte y de la Villa. Segunda edición corregida y aumentada, Madrid. Edición facsímil, Madrid, Fernando Plaza del Amo.

Romero TOBAR, Leonardo, 1974. «Nuevos datos sobre el Manual de Madrid de Mesonero Romanos», Anales del Instituto de Estudios Madrileños, X, págs. 341-345.

Rubio Cremades, Enrique, 1995. Periodismo y Literatura: Ramón de Mesonero Romanos y El Semanario Pintoresco Español, Alicante, Insituto de Cultura Juan Gil-Albert.

SALOMON, Noël, 1968. «A propos des éléments «cosrumbristas» dans Le Facundo de D. F. Sarmiento», BHi, LXX, págs. 342-412.

SARraIlH, Jean, 1925. «Le Manual de Madrid de Mesonero Romanos», RBAM, II, págs. 159-164.

StIERLE, Karlheinz, 1974. «Baudelaires «Tableaux parisiens» und die Tradition des «tableau de Paris»»», Poetica, VI, págs. 285-322. 
- 1986. «Die Entdeckung der Stadt», Medium Metropole. Berlin, Paris, New York, Heidelberg, Carl Winter Universitätverlag, págs. 81-93.

- 1993. Der Mythos von Paris. Zeichen und Bewusstsein der Stadt, München, Carl Hansen Verlag. 